\title{
Self-medication practice among undergraduate medical students of a Saudi tertiary institution
}

\author{
Osama B Albasheer ${ }^{1}$, Mohammed Salih Mahfouz ${ }^{1 *}$, Boshra M Masmali ${ }^{2}$, Rawan \\ A Ageeli ${ }^{2}$, Aisha M Majrashi ${ }^{2}$, Afaf $\mathrm{N} \mathrm{Hakami}^{2}$, Zainab $\mathrm{H}_{\text {Hakami }}{ }^{2}$, Alhanoof A \\ Hakami $^{2}$, Tahani A Douf ${ }^{2}$ \\ ${ }^{1}$ Department of Family and Community Medicine, Faculty of Medicine, ${ }^{2}$ Faculty of Medicine, Jazan University, Jazan, Kingdom \\ of Saudi Arabia
}

*For correspondence: Email: mm.mahfouz@mmahfouz.net; Tel: 0096656232711

\begin{abstract}
Purpose: To assess the knowledge, attitude and magnitude of self-medication among medical students of Jazan University, Jazan, Saudi Arabia.

Methods: A cross-sectional, self-administered questionnaire-based study was conducted among undergraduate medical students of Jazan University, Jazan, Saudi Arabia. A total of 300 students were selected by random sampling.

Results: Self-medication practice was highly prevalent among the medical students, with $87 \%$ reporting that they indulge in it. Self-medication was more prevalent among female students than male. Sedatives were the most common drugs used by students for self-medication (58\%). The most common reason adduced for self-medication practice was their belief that they have sufficient information, previous experience, and the experience of others, such as family members and colleagues, with regard to the drugs. A huge proportion (84.5\%) of the respondents agreed that selfmedication could be harmful and is associated with adverse effects, while $52.6 \%$ stated that they would not advise other persons to indulge in self-medication.

Conclusion: Self-medication is prevalent among third-year medical students of Jazan University in Saudi Arabia. Although the students exhibited sufficient awareness of self-medication, the findings highlight the need for intervention programmes regarding the practice of self-medication.
\end{abstract}

Keywords: Self-medication, Prevalence, Awareness, Sedatives, Medical students

Tropical Journal of Pharmaceutical Research is indexed by Science Citation Index (SciSearch), Scopus, International Pharmaceutical Abstract, Chemical Abstracts, Embase, Index Copernicus, EBSCO, African Index Medicus, JournalSeek, Journal Citation Reports/Science Edition, Directory of Open Access Journals (DOAJ), African Journal Online, Bioline International, Open-J-Gate and Pharmacy Abstracts

\section{INTRODUCTION}

Self-medication is widely practised worldwide, especially in developing countries as many drugs are dispensed over the counter without prescription [1,2].

Self-medication is defined as "the use of drugs to treat self-diagnosed disorders or symptoms, or the intermittent or continued use of a prescribed drug for chronic or recurrent disease or symptoms" [3]. Analgesics, antibiotics, and cough syrups are the most commonly used drugs [4]. The increase in self-medication is due to a number of factors. These factors include: ready access to drugs, socioeconomic factors, public health and environmental factors, demographic and epidemiological factors, lifestyle, the increased potential to manage certain illnesses through self-care, and greater availability of medicinal products [5]. Self-medication is especially encountered among medical students, 
which may be because of their future medical preferences [6] and the fact that medical students find themselves having more knowledge about the drugs [7].

Practising self-medication, though seen by a lot of students as a time-managing, easy and successful process, has many hazards. Misdiagnosis, delays in seeking medical advice when needed, problems of low or high drug dosage, prolonged duration of use and drug interactions, and drug abuse or dependence are well-studied adverse factors related to selfmedication [8-11].

Self-medication is not totally prohibited and the WHO sets criteria for responsible self-medication as part of self-care to improve the health care system [5]. Medicine must be of proven safety, quality and efficacy, and the conditions for which the drugs are used must be self-recognisable regarding some chronic and recurrent conditions. This practice needs active participation from pharmacists and medical professionals.

In Saudi Arabia, self-medication is common practice, although some regulations are present to control the use of over-the-counter (OTC) medications. Male gender, young age, poor health status, and dissatisfaction with health care are the most common factors [12]. A recent study in central Saudi Arabia showed that selfmedication is very common and the participants have poor knowledge and negative attitude regarding self-medication [13].

The practice of self-medication among medical students in KSA is not much studied, especially the assessment of knowledge and attitudes. In King Abdulaziz University in Jeddah, researchers reported the alarming use of self-medication with analgesics among medical students and interns, and they recommended more extensive studies on this area to assess the students' knowledge and attitude towards self-medication [14]. Another study done among medical students at the University of Al-Qassim reported that selfmedication is widely prevalent among medical students [15]. They also reported that paracetamol, antibiotics and non-steroidal antiinflammatory drugs were the most common drugs used; still, students' perception needs to be further studied. In Jazan University, no previous study was carried out on this area and the aim of this study is to assess the magnitude of this practice and to determine the students' knowledge and attitude towards self-medication.

\section{METHODS}

\section{Study setting}

Jazan University is located in Gizan, the capital of the Jazan region. The Jazan (also called Gizan) region is one of the 13 regions of the Kingdom of Saudi Arabia. It is located on the Red Sea coast in the southwestern part of the country. Jazan covers an area of 11,671 square kilometres, including some 5,000 villages and towns. It is a highly populated region with an estimated total population of 1.5 million from the last population census conducted in 2010.

\section{Study design and population}

This cross-sectional study was carried out among the undergraduate medical students of Jazan University in the period between January and February 2016. All of the medical students registered for the academic year were considered for the study.

\section{Sample size and design}

The sample size was calculated while assuming that $50 \%$ of medical students practise selfmedication, and with $6 \%$ relative precision and a $95 \%$ confidence interval the sample size was calculated to be 267 . Accounting for a nonresponse error of $10 \%$, the final sample size was calculated to be approximately 300 .

\section{Data collection}

A pre-designed, semi-structured questionnaire was used to collect the relevant information pertaining to the study variables. The questionnaire had two sections: the first section consisted of questions regarding age, gender, year of the participating students, and students' college. The second section consisted of questions regarding the practice of selfmedication and attitude and perception regarding self-medication.

\section{Data analysis}

SPSS version 20 (SPSS Inc, Chicago, IL, USA) was used for data analysis. Statistical analysis involved descriptive statistics as well as inferential statistics. Descriptive statistics included a simple tabulation, frequencies, and the proportion of categorical variables (including cross-tabulations). Continuous variables were presented as mean \pm standard deviation (SD). Categorical variables were compared for significance using the chi-square test. $P<0.05$ was used to indicate statistical significance. 


\section{Ethical consideration}

Approval for the current study was obtained from the college of Medicine (CLC 432-2015/2016 Module). Written consent forms were obtained from all study participants. The rights of the students to participate or withdraw at any time were explained. Data privacy and confidentiality were maintained throughout the research.

\section{RESULTS}

Association between prevalence of selfmedication and participants' characteristics

The total number of participants was that of 300 medical students (50\% male, $50 \%$ female). The average age for participants was 21 (Table 1).

Table 1: Demographic profile of study participants

\begin{tabular}{ccc}
\hline Characteristic & No. & $\%$ \\
\hline Age (years) & & \\
$19-20$ & 74 & 24.7 \\
$21-22$ & 109 & 36.3 \\
$23-24$ & 117 & 39.0 \\
Gender & & \\
Male & 150 & 50.0 \\
Female & 150 & 50.0 \\
Study Level & & \\
$2^{\text {nd }}$ year & 60 & 20.0 \\
$3^{\text {rd }}$ year & 60 & 20.0 \\
$4^{\text {th }}$ year & 60 & 20.0 \\
$5^{\text {th }}$ year & 60 & 20.0 \\
$6^{\text {th }}$ year & 60 & 20.0 \\
Total $^{\text {Meal }}$ & 300 & 100 \\
\hline
\end{tabular}

The overall prevalence among users was 83.7 $\%$. Female medical students practised selfmedication slightly more than male students (85.0 and 81.3 respectively). The prevalence was slightly higher at ages 22 and $23(p=0.059)$. There was no significant variation in the prevalence of users when related to the levels of students (Table 2).

Among those who reported self-medication, $69 \%$ used it for pain management, $45 \%$ for cold symptoms, $34 \%$ for heart burn, $23 \%$ for migraine headache, $19 \%$ for skin problems, 16 $\%$ to treat constipation, and $15.7 \%$ to treat diarrhoea (Figure 1).

Figure 2 shows what influenced students to indulge in self-medication. It was observed that $44.4 \%$ of males and $36.2 \%$ of females indicated that they have a good idea about diseases and their drug management. Furthermore, $29.1 \%$ of males and $36.2 \%$ of females said they practised self-medication because of their previous experience with the drug. Also, $17.9 \%$ of males and $11.0 \%$ of females practised self-medication because of the experience of others, e.g. family members and colleagues, with the drug.

\section{Knowledge and attitude of students towards self-medication}

Table 3 shows the knowledge and attitude of students towards self-medication. It indicates that $84.5 \%$ of the respondents agreed that selfmedication could be serious and associated with adverse effects. There were no significant differences between males and females $(p=$ 0.079 ). With regard to whether they would encourage others to indulge in self-medication, $47.4 \%$ of respondents responded in the affirmative, stating that it is simple and effective, while $52.6 \%$ said that self-medication is a serious issue.

Table 2: Prevalence of self-medication practice among study participants

\begin{tabular}{|c|c|c|c|c|}
\hline Characteristic & $\begin{array}{c}\text { Self-medication users/ } \\
\text { Total }\end{array}$ & Prevalence & $95 \% \mathrm{Cl}$ & $P$-value \\
\hline Age (years) & & & & 0.059 \\
\hline 19 & $(12 / 17)$ & 70.6 & $46.5-86.7$ & \\
\hline 20 & $(48 / 57)$ & 84.2 & $72.6-91.4$ & \\
\hline 21 & $(50 / 63)$ & 79.4 & $67.8-87.4$ & \\
\hline 22 & $(44 / 46)$ & 95.7 & $85.5-98.7$ & \\
\hline 23 & $(58 / 66)$ & 87.9 & $77.8-93.7$ & \\
\hline 24 & $(39 / 51)$ & 76.5 & $63.2-86.0$ & \\
\hline Gender & & & & 0.274 \\
\hline Male & $(122 / 150)$ & 81.3 & $74.3-86.7$ & \\
\hline Female & $(129 / 150)$ & 86.0 & $79.5-90.6$ & \\
\hline Study Level & & & & 0.374 \\
\hline $2^{\text {na }}$ year & $(48 / 60)$ & 80.0 & $46.5-76.8$ & \\
\hline $3^{\text {ra }}$ year & $(48 / 60)$ & 80.0 & $46.5-76.8$ & \\
\hline $4^{\text {th }}$ year & $(55 / 60)$ & 91.7 & $81.9-96.3$ & \\
\hline $5^{\text {th }}$ year & $(49 / 60)$ & 81.7 & $70.0-89.4$ & \\
\hline $6^{\text {th }}$ year & $(51 / 60)$ & 85.0 & $73.8-91.8$ & \\
\hline Overall prevalence & $(251 / 300)$ & 83.7 & $79.1-87.4$ & \\
\hline
\end{tabular}




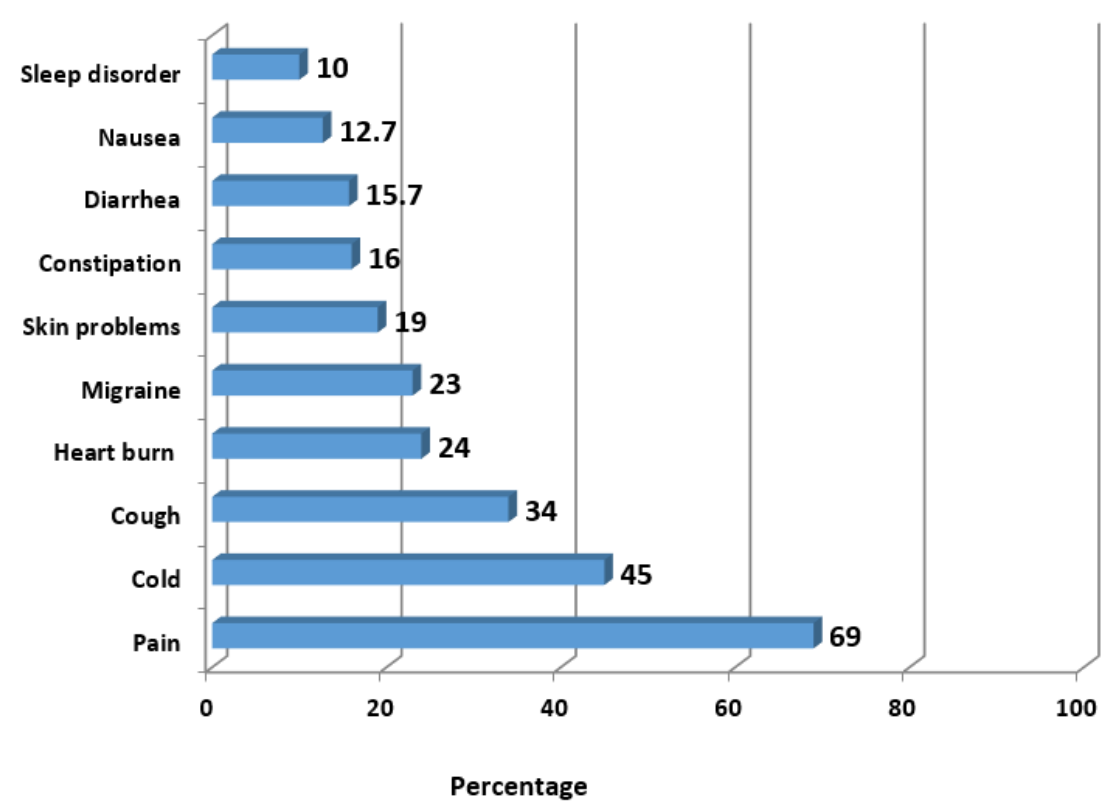

Figure 1: Main reasons for self-medication among study participants

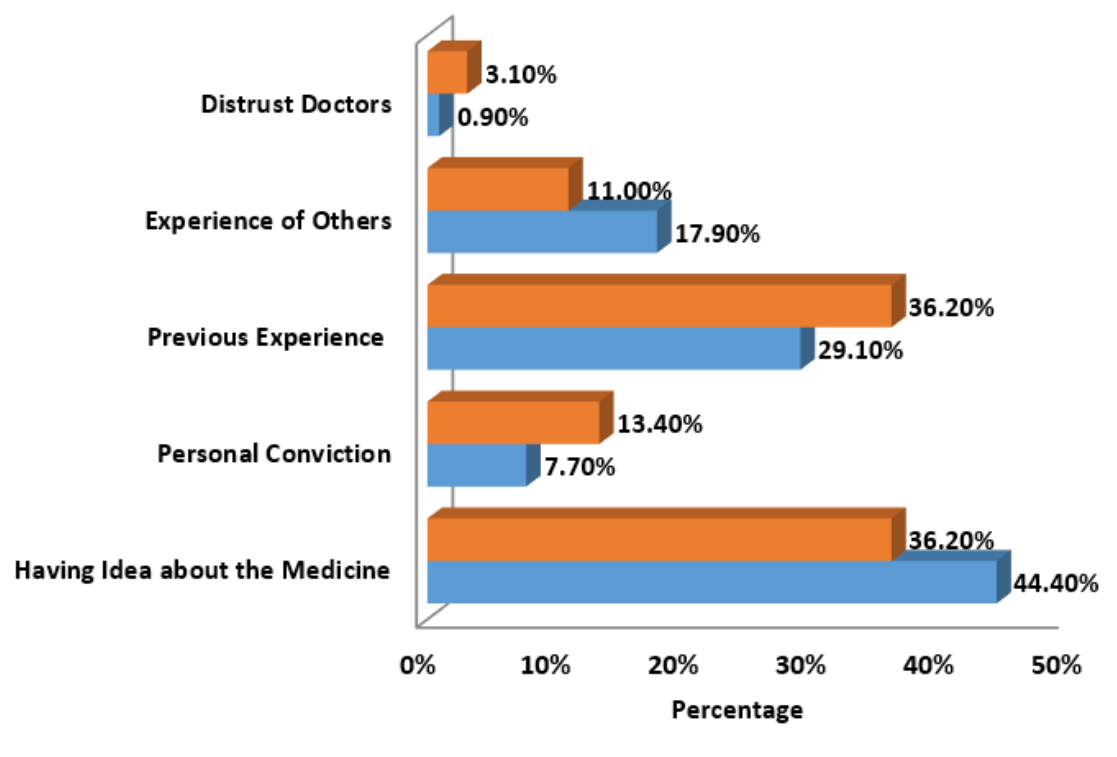

Female Male

Figure 2: Factors responsible for self-medication

Moreover, $80.9 \%$ of the participants made effort to obtain information about a drug before using it, while $75.3 \%$ read the product leaflet. There were very significant differences between male and female students with regard to the source of information $(p=0.000)$, as male students rely more on doctors and pharmacists (52.5 and 21.3 $\%$, respectively) for their information about drugs, while female students rely much more on reading product leaflets and the Internet (18.6 and 33.3 $\%$, respectively).

Drugs commonly used by students for selfmedication are shown in Table 4. Sedatives were the most commonly used group of drugs (70.1 $\%$ ), followed by antibiotics (18.3\%), anti-allergy (5.6 \%), multivitamins (2 \%), anti-inflammatory (1.2\%), and others (mainly drugs used for chronic problems: $2.8 \%$ ). There was no significant difference between males and females in the use of these groups of medication ( $p=$ 0.368). The same table showed that male students used more types of drugs for selfmedication ( $p=0.069)$, while female students used fewer types of drugs but more frequently than male students $(p=0.045)$.

Trop J Pharm Res, October 2016; 15(10): 2256 
Table 3: Attitude of medical students regarding self-medication

\begin{tabular}{|c|c|c|c|c|}
\hline Variable & Male & Female & Total & $P$-value \\
\hline \multicolumn{5}{|l|}{$\begin{array}{l}\text { Self-medication may cause adverse } \\
\text { drug reactions }\end{array}$} \\
\hline Yes & $98(80.3)$ & $114(88.4)$ & 212(84.5) & 0.079 \\
\hline No & 24(19.7) & $15(11.6)$ & $39(15.5)$ & \\
\hline \multicolumn{5}{|l|}{ Source of information on drug use } \\
\hline Doctor & $64(52.5)$ & $42(32.6)$ & $106(42.2)$ & 0.000 \\
\hline Pharmacist & $26(21.3)$ & $14(10.9)$ & $40(15.9)$ & \\
\hline Friends & $3(2.5)$ & $6(4.7)$ & $9(3.6)$ & \\
\hline Drug product leaflet & $10(8.2)$ & 24(18.6) & $34(13.5)$ & \\
\hline Internet & $19(15.6)$ & $43(33.3)$ & $62(24.7)$ & \\
\hline $\begin{array}{l}\text { Did you made any effort to obtain } \\
\text { information about the medicine before } \\
\text { using it? }\end{array}$ & & & & 0.239 \\
\hline Yes & $95(77.9)$ & $108(83.7)$ & 203(80.9) & \\
\hline No & $27(22.1)$ & $21(16.3)^{\prime}$ & $48(19.1)$ & \\
\hline Do you read drug product leaflets? & & & & 0.044 \\
\hline Yes & $85(69.7)$ & 104(80.6) & $189(75.3)$ & \\
\hline No & $37(30.3)$ & $25(19.4)$ & $62(24.7)$ & \\
\hline $\begin{array}{l}\text { Would you encourage to indulge in } \\
\text { self-medication? }\end{array}$ & & & & 0.769 \\
\hline Yes & $59(48.4)$ & $60(46.5)$ & $119(47.4)$ & \\
\hline No & $63(51.6)$ & $69(53.5)$ & 132(52.6) & \\
\hline
\end{tabular}

Table 4: Distribution of medicine under different therapeutic category and pattern of use

\begin{tabular}{|c|c|c|c|c|}
\hline Drug category & Male & Female & Total & P-value \\
\hline \multicolumn{5}{|l|}{ Type of drug used } \\
\hline Sedative & $85(69.7)$ & $91(70.5)$ & $176(70.1)$ & \\
\hline Antibiotics & $28(23.0)$ & $18(14.0)$ & $46(18.3)$ & \\
\hline Vitamins & $3(2.5)$ & $2(1.6)$ & $5(2.0)$ & \\
\hline Anti-allergy & $3(2.5)$ & $11(8.5)$ & $14(5.6)$ & \\
\hline Anti-inflammatory & $2(1.6)$ & $1(0.8)$ & $3(1.2)$ & 0.368 \\
\hline Others & $1(.8)$ & $6(4.7)$ & $7(2.8)$ & \\
\hline $\begin{array}{l}\text { No. of drugs used for } \\
\text { self-medication }\end{array}$ & & & & 0.069 \\
\hline$<5$ & $203(80.9)$ & $110(85.3)$ & $93(76.2)$ & \\
\hline$>5$ & $48(19.1)$ & $19(14.7)$ & $29(23.8)$ & \\
\hline $\begin{array}{l}\text { No. of times of } \\
\text { indulged in self- } \\
\text { medication }\end{array}$ & & & & 0.045 \\
\hline Fewer than five times & $115(45.8)$ & $67(51.9)$ & $48(39.3)$ & \\
\hline More than five times & $136(54.2)$ & $62(48.1)$ & $74(60.7)$ & \\
\hline
\end{tabular}

\section{DISCUSSION}

The study revealed that the prevalence of selfmedication practice was high among medical students in Jazan University. This finding is similar to other studies, where the prevalence of self-medication amongst students has ranged from 43.24 to $98 \%[6,7]$. Most of the students find themselves having much knowledge about the drug. The same result was reported by Gillian Meauri in his study among students at the University of Papua New Guinea [7]. In addition to the knowledge, the high prevalence of selfmedication could be related to the simple nature of diseases encountered by the students, and the time factor (as most students find it difficult to have appropriate medical appointments during study hours).

As published in many studies, the most common problems for which students used selfmedication were vague pain (69\%), cold symptoms (45\%), heart burn (34\%), migraine headache $(23 \%)$, and skin problems (19\%) $[16,17]$. Sedatives and antibiotics are the most commonly used drugs for self-medication. This finding is in keeping with other studies which posited that the commonest groups of medication prone to self-medication include sedatives, antibiotics, and anti-allergy $[4,15]$. The ready availability of these groups of drugs, even without prescription, is the main reason behind the high intake of them by the students. Irrational use of antibiotics may result in the emergence of 
resistant strains and increased cost and morbidity.

Self-medication was considered to be serious and associated with adverse effects by the majority of students, both male and female. This could be because medical students are aware of the fact that no drug is totally safe and each can have adverse effects, ranging from mild to severe. The knowledge about self-medication was found to be appropriate in male and female medical students, as the majority of them try to read about the drugs before use and they even read the bulletins attached to the drugs; still, measures should be taken to ensure proper safety of the drugs and that the drugs are used for the right condition. Furthermore, our study revealed that gender is important in determining the source of information for self-medication. Male students depend more on doctors and pharmacists, while female students depend more on reading and Internet searching.

Our study revealed that medical students have had a more cautious attitude towards selfmedication, reflected by the fact that the majority of them agreed that self-medication could be serious and more than half of them disagreed with advising others upon self-medication. This finding is in contrast to a study done in central Saudi Arabia to assess the knowledge, attitudes and perception of consumers towards selfmedication, where the participants exhibited poor knowledge and negative attitude towards selfmedication [13]. This obvious difference in knowledge and attitude is expected, as medical students are more aware of the use of drugs, as they study them in their medical curriculum.

\section{Limitations of the study}

This study was based on a cross-sectional survey design. Thus, the direction of relationships and causal relationships cannot be determined. In addition, the use of a selfadministered questionnaire on self-medication may produce subjective measurements that are less reliable than objective methods. Finally, this study was only performed among undergraduate medical students and thus would not be applicable to students in other disciplines or even medical students in other years of their study.

\section{CONCLUSION}

Self-medication practice is prevalent among third-year medical students of Jazan University, Jazan, Saudi Arabia. Although the students exhibited some awareness of self-medication, the findings of this study highlight the need for intervention programmes to minimize indulgence in self-medication.

\section{DECLARATIONS}

\section{Acknowledgement}

The authors are thankful to faculty members of Department of Family and Community Medicine, Faculty of Medicine, Jazan University for their help and support. Thanks are also due to the study respondents.

\section{Conflict of Interest}

No conflict of interest associated with this work.

\section{Contribution of Authors}

The authors declare that this work was done by the authors named in this article and all liabilities pertaining to claims relating to the content of this article will be borne by them.

\section{REFERENCES}

1. Geissler PW, Nokes K, Prince RJ, Achieng RO, AagaardHansen J, Ouma JH. Children and medicines: Selftreatment of common illnesses among Luo schoolchildren in western Kenya. Soc Sci Med. 2000; 50: 1771-1783.

2. Hussain S, Malik F, Hameed A, Ahmad S, Riaz $H$. Exploring health seeking behavior, medicine use and self-medication in rural and urban Pakistan. South Med Rev. 2010; 3(2): 32-35.

3. Awad A, Eltayeb I, Matowe L, Thalib L. Self-medication with Antibiotics and Antimalarials in the Community of Khartoum State, Sudan. J Pharm Pharm Sci. 2005; 2(8): 326-331.

4. Afolabi AO. Factors influencing the pattern of selfmedication in an adult Nigerian population. Ann Afr Med. 2000; 7(3): 120-127.

5. World Health Organization. The Role of Pharmacists in Health Care System. [Internet]. 1998. Available from: World Health Organization. 1998. Available from: http://www.apps.who.int/medicinedocs/en/d/Jwhozip32e [last accessed on Apr 25, 2009].

6. Banerjee I, Bhadury T. Self-medication practice among undergraduate medical students in a tertiary care medical college, West Bengal. J Postgr Med. 2012; 58(2): 127-131.

7. Meauri G, Temple V, Law F. Prevalence of selfmedication among students in Papua New Guinea. Pacific J Med Sci. 2013; 9(1): 17-31.

8. Hughes CM, McElnay JC, Fleming GF. Benefits and risks of self-medication. Drug Saf. 2001; 24(14): 1027-1037.

9. Ferris DG, Nyirjesy P, Sobel JD, Soper D, Pavleti CA, Litaker MS. Over-the-counter antifungal drug misuse

Trop J Pharm Res, October 2016; 15(10): 2258 
associated with patient-diagnosed vulvovaginal candidiasis. Obstet Gynecol. 2002; 99: 419-425.

10. Calabresi P, Cupini LM. Medication-overuse headache: similarities with drug addiction. Trends Pharmacol Sci. 2005; 26(2): 62-68.

11. Ruiz ME. Risks of self-medication practices. Curr Drug Saf. 2010; 4(5): 315-323.

12. Alghanim SA. Self-medication practice among patients in a public healthcare system. East Mediterr Heal J. 2011; 17: 409-416.

13. Aljadhey H, Assiri GA, Mahmoud MA, Al-Aqeel S, Murray M. Self-medication in Central Saudi Arabia: Community pharmacy consumers' perspectives. Saudi Med J. 2015; 36(3): 328-334.

14. Ibrahim NK, Alamoudi BM, Baamer WO, Al-Raddadi RM. Self-medication with analgesics among medical students and interns in King Abdulaziz University, Jeddah, Saudi Arabia. Pak J Med Sci. 2015; 31(1): 1418.

15. Saeed MS, Alkhoshaiban AS, Al-Worafi YM, Long CM. Perception of self-medication among university students in Saudi Arabia. Arch Pharm Pract. 2014; 5(4): 149152.

16. Gutema GB, Gadisa DA, Kidanemariam ZA, Berhe $D F$, Berhe AH, Hadera MG, Hailu GS, Abrha NG. Selfmedication practices among health sciences students: the case of Mekelle University. J Appl Pharma Sci. 2011; 1(10): 183-189.

17. Nalini GK. Self-medication amongst allopathic doctors in Karnataka, India. Br J Med Pr. 2010; 3(2): 325. 